\title{
Les enzymes d'origine microbienne et leur emploi dans l'affinage des fromages
}

\author{
par \\ J. LENOIR (1), R. VEISSEYRE (1), J. HERMIER (2), G MOCQUOT (2), \\ G. BRET (3)*, M. GALZIN (3) et F. ARDIN (3) \\ (1) Laboratoire de Technologie de l'Ecole Nationale Supérieure \\ Agronomique de Grignon (78) \\ (2) Station Centrale de Recherches Laitières et de Technologie \\ des Produits Animaux, C.N.R.Z., Jouy-en-Josas (78) \\ (3) Société des Caves de Roquefort (12)
}

La fromagerie a connu au cours des vingt dernières années une évolution marquée. Elle dispose maintenant de procédés permettant de coaguler le lait et d'égoutter le coagulum, selon des techniques réellement industrielles ; la mécanisation des opérations et le développement de procédés continus permettent la mise en place d'unités de production importantes sur lesquelles on peut exercer un contrôle régulier et systématique.

Il n'en est pas de même en ce qui concerne l'affinage. Il y a encore, dans la conduite de ce phénomène complexe, une grande part d'empirisme et les conditions dans lesquelles il est réalisé demeurent artisanales.

Dans chaque fraction de caillé mise en forme, la maturation de la pâte et la formation de la saveur et de l'arôme, sont commandées par le développement et l'activité des micro-organismes. Le fromager doit s'attacher à assurer dans chaque pièce de fromage le peuplement et le développement microbiens propres à créer les activités enzymatiques nécessaires à l'évolution souhaitée des constituants. En somme, pour une fabrication d'un type donné, au sein de chaque pièce de fromage, doivent être élaborées les enzymes responsables de sa propre transformation.

Ces conditions de travail ne sont guère favorables à une " industrialisation " de l'affinage qui suppose une réelle maîtrise du processus de maturation. Or, il est vraisemblable que seule une modifi-

\footnotetext{
* Adresse actuelle : 88 Van Boetzelaerlaan, La Haye (Hollande).
} 
cation profonde des modalités de l'affinage permettra d'accéder à une telle maîtrise.

Peut-on dès aujourd'hui envisager la mise en œuvre de ces méthodes d'affinage plus rationnelles ? A priori, l'emploi d'enzymes microbiennes produites industriellement peut offrir dans ce domaine d'intéressantes possibilités.

Introduire dans le lait de fabrication ou dans la masse du caillé des préparations enzymatiques d'activité connue, contrôlée, devrait en effet permettre d'orienter, de maîtriser les phénomèmes biochimiques majeurs de la maturation, la protéolyse et la lipolyse.

Certes, il existe de nombreux micro-organismes capables de produire des protéases et des lipases ; certains sont déjà cultivés à l'échelle industrielle pour la production d'enzymes utilisées dans divers secteurs. Il semble cependant naturel, dans la perspective d'un emploi en fromagerie, de choisir comme matériel des microorganismes qui jouent un rôle dominant dans la maturation des fromages traditionnels. Aussi, avons-nous porté notre attention, en premier lieu, sur les moisissures Penicillium caseicolum et Penicillium roqueforti, agents de la maturation de nombreux fromages à pâte molle ou de fromages persillés.

Un programme de recherche qui fait l'objet d'une Convention de la D.G.R.S.T. est actuellement en cours dans nos trois laboratoires depuis janvier 1968. Il porte essentiellement sur les points suivants:

- une sélection des souches comportant la constitution d'une collection, la détermination des aptitudes à la production d'enzymes, la caractérisation des protéases et des lipases produites,

- une étude des facteurs de production des enzymes,

- la purification et l'identification des enzymes,

- la détermination des conditions d'emploi et des caractères technologiques des enzymes par essais systématiques en fabrications fromagères expérimentales.

L'intérêt de ces travaux est certain. Mieux connaître les aptitudes biochimiques des micro-organismes, les conditions de production des enzymes, les caractères des systèmes enzymatiques et notamment la nature des produits formés, sont autant de préoccupations pour le microbiologiste et le biochimiste. Mais c'est au stade de l'application et du développement industriels que la recherche en cours devrait avoir les prolongements les plus importants.

La préparation d'extraits enzymatiques, suffisamment concentrés et stables pour être utilisés en fromagerie, est susceptible de modifier profondément et dans un sens très favorable les conditions de l'affinage. Une orientation précise, un contrôle rigoureux et finalement une planification des transformations biochimiques des constituants $\mathrm{du}$ - caillé devraient devenir possibles. Simultanément une accélération considérable du processus de maturation pourrait être envisagée. Ainsi, des fabrications de masse de qualité plus régulière, 
obtenues dans un temps plus court, pourraient être plus aisément assurées que par les techniques traditionnelles. Avec l'emploi des enzymes produites par les moisissures du genre Penicillium ces avantages seraient particulièrement appréciés dans le cas de la fabrication des fromages à pâte molle, de petit format, qui représentent actuellement près de 50 p. 100 de la production fromagère française et dont la qualité est trop souvent hétérogène.

Sans doute, ces perspectives exigeront-elles un certain délai ; l'étude n'est qu'ébauchée et le programme de travail actuel limité à l'utilisation en fabrications expérimentales. Les résultats obtenus ne seront probablement pas directement transposables au plan des fabrications industrielles. Des correctifs, des aménagements, la mise au point de fabrications-types seront certainement nécessaires. D'ores et déjà il est permis de penser que l'utilisation des enzymes d'origine microbienne, pour être pleinement satisfaisante, devra se situer dans le cadre d'une technologie nouvelle, originale, tant dans la technique de préparation du caillé que dans les conditions de l'affinage. Une telle technologie pourrait naturellement être à l'origine de nombreux produits laitiers nouveaux. 